\title{
Publisher Correction: Population reference and healthy standard blood pressure range charts in pregnancy: findings from the Born in Bradford cohort study
}

\author{
Gillian Santorelli $\mathbb{D}$, Debbie A. Lawlor, Jane West $\mathbb{D}$, Derek Tuffnell \& Diane Farrar $\mathbb{D}$ \\ Correction to: Scientific Reports https://doi.org/10.1038/s41598-019-55324-2, published online 11 December
} 2019

This Article contains a typographical error in the Methods section under subheading 'Participants' where,

"The following exclusions were applied: still births ( $\mathrm{n}$ he59), multiple births (n 9)138), pregnancies resulting in the birth of children with congenital anomalies (n 38649), and women who had missing baseline questionnaire or birth outcome data (n 49831)."

should read:

“The following exclusions were applied: still births $(n=59)$, multiple births $(n=138)$, pregnancies resulting in the birth of children with congenital anomalies $(n=649)$, and women who had missing baseline questionnaire or birth outcome data $(\mathrm{n}=831)$."

In addition there is a typographical error in the Methods section under subheading 'Statistical Analysis' where,

"The shape of the BP trajectory across pregnancy was described by fitting restricted cubic splines using knot points which have been previously identified in the same dataset using linear splines (at 24, 30 and 36 weeks), with two additional outer knots at the 5th and 9th percentiles of the data (14 and 40 weeks)."

should read:

"The shape of the BP trajectory across pregnancy was described by fitting restricted cubic splines using knot points which have been previously identified in the same dataset using linear splines (at 24, 30 and 36 weeks), with two additional outer knots at the 5th and 95th percentiles of the data (14 and 40 weeks)."

(i) Open Access This article is licensed under a Creative Commons Attribution 4.0 International License, which permits use, sharing, adaptation, distribution and reproduction in any medium or format, as long as you give appropriate credit to the original author(s) and the source, provide a link to the Creative Commons license, and indicate if changes were made. The images or other third party material in this article are included in the article's Creative Commons license, unless indicated otherwise in a credit line to the material. If material is not included in the article's Creative Commons license and your intended use is not permitted by statutory regulation or exceeds the permitted use, you will need to obtain permission directly from the copyright holder. To view a copy of this license, visit http://creativecommons.org/licenses/by/4.0/.

(C) The Author(s) 2020 